\section{Voluntary HIV test launched} for women

\section{London}

THE British government is to launch a programme of voluntary screening for the human immunodeficiency virus (HIV) in a sample of around 90,000 pregnant women over a one-year period. The number represents about a sixth of all pregnant women. The government may sanction involuntary testing, but not before widespread consultation on the legal and ethical issues, for which health minister Tony Newton has invited views.

By deciding to opt for voluntary testing, the government is accepting the recommendations of a working party set up last year under Dr Joe Smith, director of the Public Health Laboratory Service. Smith's report, The Monitoring and Surveillance of HIV Infection and AIDS (Department of Health and Social Security, London, £2.00) rules out involuntary, anonymous testing at first, "as we believe that the data required for the surveillance of HIV infection in the UK can be obtained by means of studies in which the consent of the patient has been secured".

The women would be given the choice to have the test done anonymously, in which case they would not be identified or learn the outcome. "In this way the bias due to individuals refusing to be tested may be reduced appreciably". Several of the country's leading epidemiologists have insisted that compulsory screening of all pregnant women is the only feasible means of obtaining an idea of the prevalence of HIV in the general population. It remains questionable, however, whether using a patient's blood for a purpose not specified is legal. The British Medical Association has said that such a move could amount to criminal assault.

For the study, three samples of pregnant women will be tested, each of the order of 20,000 to 30,000 women. Two samples will be from relatively high-risk areas - one in London and one in Scotland - and the third from a low risk area. The workshop group is confident that the size of the sample is adequate to obtain an accurate figure for the prevalence of the infection and that refusal rates are likely to be low because of the clinical value to the woman and the child.

Not everyone shares the group's confidence on the issue of refusal rates. Professor David Cox, of Imperial College, says that while the government's initiative was to be welcomed as a move in the right direction, the requirement for participants to volunteer leaves "an enormous question mark" over the eventual success of the study.

Simon Hadlington

AIDS prevalence in pregnant women in France cause for worry

Paris

A RECENT study in of 274,647 pregnant women in France has revealed that as many as two births or abortions per day involve women carrying antibodies to the human immunodeficiency virus (HIV), the virus causing AIDS. Over one third of these women testing seropositive had no idea that they were at risk. The Health Ministry now has to decide what action, if any, should be taken in the light of these results, but is finding that the options are not simple.

The survey was carried out on the initiative of Professor Roger Henrion, an obstretrician at the Port Royal maternity hospital in Paris, with support from the Direction Générale de la Santé (public health directorate). Following a preliminary study in the Greater Paris area in 1987, Henrion extended his research to cover 239 clinics throughout France. The final sample represents over one third of the 778,000 births in France during 1987.

Although the health ministry has questioned the representativeness of the sample (because of geographical variation and because few private clinics were approached), the results give the best idea available of the spread of the AIDS virus among young French women. In particular, it confirms that the virus is so far concentrated in two metropolitan areas Paris/Ile de France and Provence/Côte d'Azur - and that intravenous drug-users constitute the female population most at risk (66.7 per cent of the sample testing seropositive). Sexual contact is the next most common means of transmission.

An AIDS test is systematically proposed to pregnant women in only a minority of French clinics. (At present, only donors of blood, organs or sperm are required, by law, to be screened for HIV.) Other clinics propose an AIDS test only to patients identified as belonging to a highrisk group. The results therefore probably underestimate the true incidence of the AIDS virus among young women.

Although he thinks nationwide systematic screening is not yet warranted, Henrion believes there is justification for systematic voluntary screening where the risk of AIDS infection is high. Current statistics suggest that one out of two children born to seropositive women develop and almost certainly die of - AIDS before the age of five. The speed with which a paediatrician can react with appropriate therapies when a baby falls ill is greatly increased if the child is known to be seropositive. This would be even more necessary should a vaccine or treatment for AIDS be found.

The health ministry wants to see Henrion's study extended to overcome statistical flaws. But the minister is not yet convinced that the cost of systematic voluntary screening of pregnant women is justified.

Peter Coles

\title{
French AIDS figures highest in Europe
}

Paris

Sratistics published by the World Health Organization (WHO) reveal that, with an estimated 63.5 AIDS sufferers per million inhabitants, France now has the highest incidence of known AIDS cases in the European Community (EC). The next highest is in Denmark (51.4 cases per million), followed by Belgium (33.9 cases per million).

Male homosexuals still comprise the majority of AIDS sufferers but the disease is spreading most rapidly among intravenous drug users. The new Health Minister, Claude Evin, decided last week to extend for a further year the sale of disposable hypodermic syringes without prescription. But a small survey of $\mathbf{3 0 0}$ addicts carried out for the Ministry of Health found that almost half of the sample still share syringes.

The French government Health Department (Direction Générale de la Santé) has found that, if current growth rates are projected, 21,101 cases of AIDS will have been diagnosed by the end of 1989 , with as many as half needing hospital treatment.

At present almost 70 per cent of AIDS sufferers are treated in the five specialized clinics in Paris. A further six clinics have been set up in the provinces, but screening for the virus causing AIDS still remains a problem. Although anonymous free tests are available, with 100 centres to be opened in France by the end of 1988, the addresses of existing centres are not well publicized.

The cost of an ELISA test (about £14) is reimbursed only for those having valid state or private health insurance. Although the results of the test are not shown on the insurance form, the claim for reimbursement cannot be anonymous. This system is thought to dissuade some of those potentially at risk from taking an AIDS test. But Médecins du Monde, a charity run by doctors, has had to open a second Paris centre to cope with the demand for its nononsense, free, anonymous screening service. The state health service is now thinking of adopting a similar procedure in its new centres. 